\title{
Abstract
}

\section{Identification of novel vaccine candidate antigens using phage display technology}

\author{
J. Newcombe and J. McFadden \\ SBLS University of Surrey, Guildford, Surrey, GU2 \\ $7 X H, U K$
}

There is a need to develop a new vaccine that is effective for group B meningococcal disease. We are currently using phage display technology to identify new candidate antigens. Our approach is to screen a meningococcal expression library (expressed on the surface of a phage) with convalescent sera taken from meningitis patients. Our assumption is that convalescent sera will contain antibodies that bind to protective antigens. Genomic DNA from Neisseria meningitidis
H44/76 (B15: PI 7,16) was DNAse treated to generate random fragments of between 100 and 300bp that were blunt ended and cloned into the M13 phagemid vector, pHEN-1 (Hoogenboom, H.R. et al., NAR 1991, $19,4133)$, to generate a genomic library of 350,000 clones. The library was screened by biopanning to identify phage that bind to antibodies present in convalescent sera, but absent in acute sera. Three rounds of biopanning were performed and individual clones from the convalescent sera-enriched library were subjected to DNA sequence analysis. A number of meningococcal proteins were identified including outer membrane proteins. 


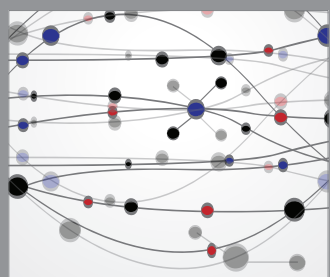

The Scientific World Journal
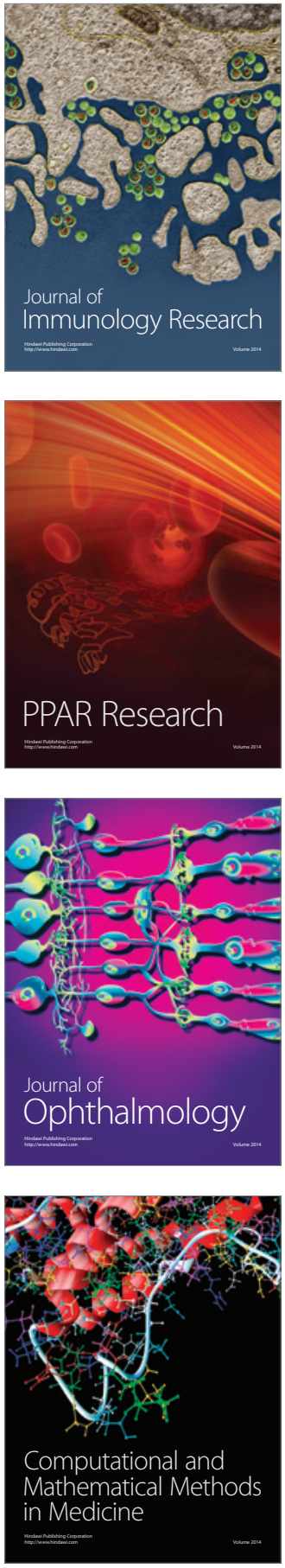

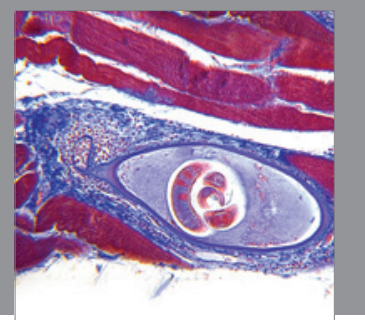

Gastroenterology

Research and Practice
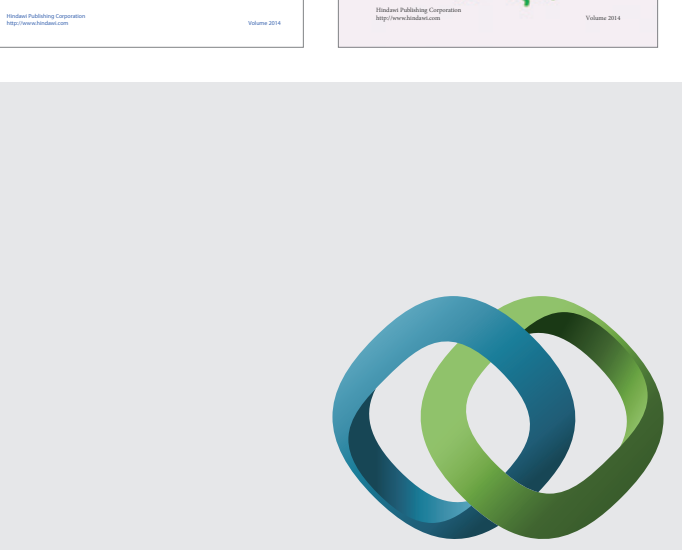

\section{Hindawi}

Submit your manuscripts at

http://www.hindawi.com
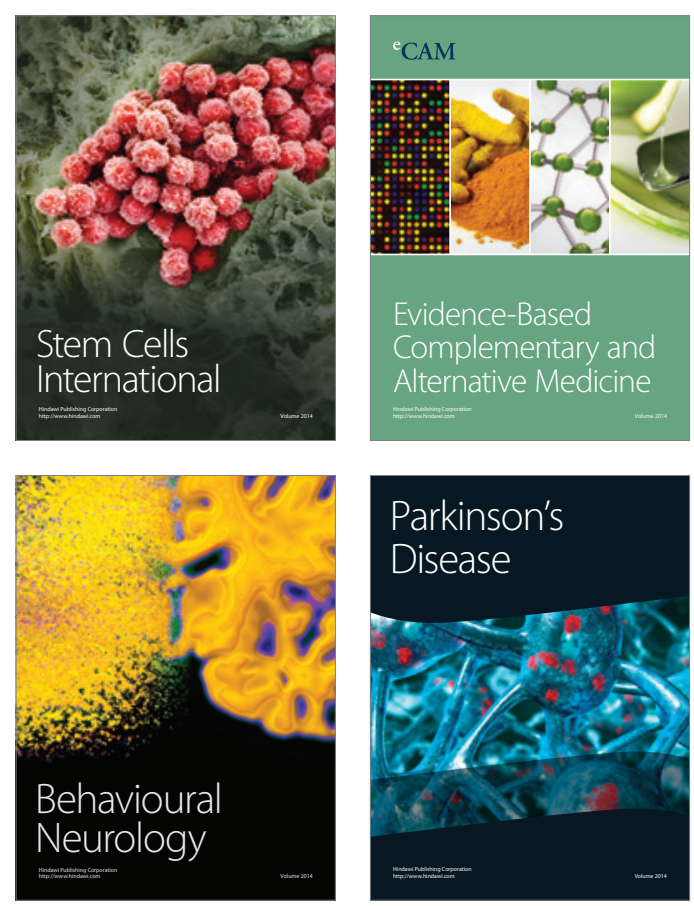

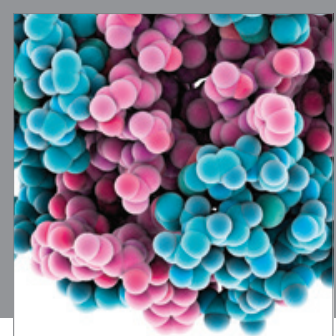

Journal of
Diabetes Research

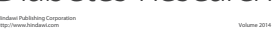

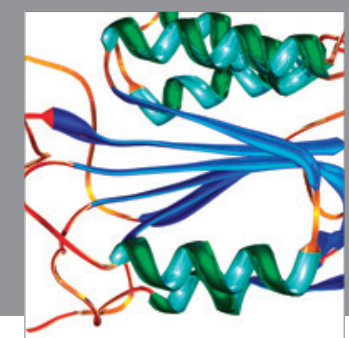

Disease Markers
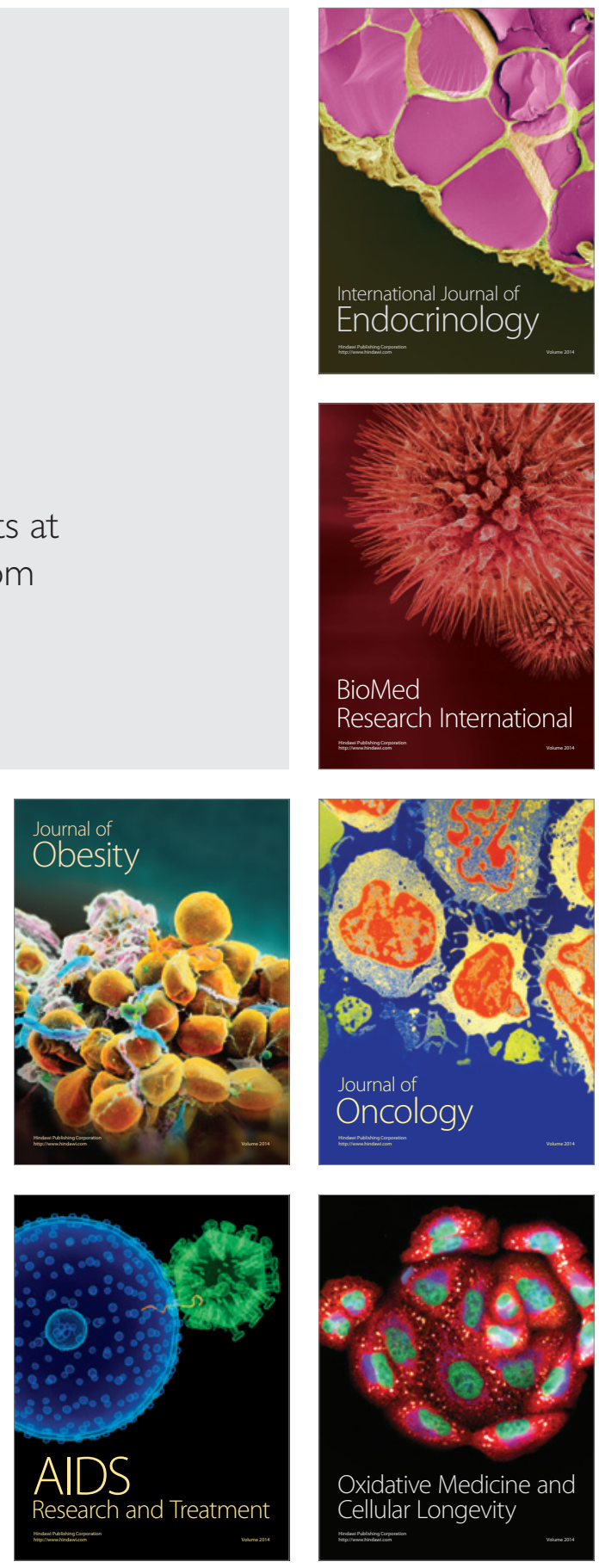